\title{
Preferences for WeChat-Based and Hospital-Based Family Intervention Among Caregivers of People Living with Schizophrenia
}

\author{
Xiantao Zhang $\mathbb{D}^{1, *}$, Bibo Liu' ${ }^{1, *}$, Difan Zang', Yilu Li', Shuiyuan Xiao', Yu Yu $\mathbb{D}^{1,2}$ \\ 'Department of Social Medicine and Health Management, Xiangya School of Public Health, Central South University, Changsha, Hunan, People's \\ Republic of China; '2Division of Prevention and Community Research, Department of Psychiatry, Yale School of Medicine, New Haven, CT, USA \\ *These authors contributed equally to this work
}

Correspondence: Yu Yu, Department of Social Medicine and Health Management, Xiangya School of Public Health, Central South University, Upper Mayuanlin Road 238, Changsha, Hunan, 410008, People’s Republic of China, Tel + I 203745953I, Email yu.yu@yale.edu

Purpose: This study examines the preferences for WeChat-based and hospital-based family intervention among caregivers of people living with schizophrenia (PLS) and identify correlates associated with these preferences.

Patients and Methods: A cross-sectional study was conducted with 449 family caregivers of PLS. Face-to-face interviews were conducted to collect information on socio-demographics, preferences for WeChat-based and hospital-based family intervention, social support, and coping.

Results: Over $72.16 \%$ of participants endorsed hospital-based family intervention, while $50.11 \%$ endorsed WeChat-based family intervention. Endorsement of WeChat-based family intervention was associated with younger age (OR=0.42, 95\% CI: $0.22,0.79)$, WeChat use $(\mathrm{OR}=12.90,95 \% \mathrm{CI}: 7.48,22.23)$, and higher social support $(\mathrm{OR}=1.03,95 \% \mathrm{CI}: 1.01,1.04)$. Endorsement of hospital-based family intervention was associated with lower education $(\mathrm{OR}=0.19-0.37,95 \% \mathrm{CI}: 0.07,0.66)$ and WeChat use (OR=3.27, 95\% CI: $1.91,5.59)$.

Conclusion: The studies showed a higher endorsement rate for hospital-based family intervention than WeChat-based family intervention and provide implications for developing targeted family intervention programs based on participants' own unique characteristics.

Keywords: preference, WeChat, caregiving, schizophrenia

\section{Introduction}

Schizophrenia is a chronic deliberating mental disease that requires long-term care, and family plays a vital role in the rehabilitation of people living with schizophrenia (PLS). ${ }^{1}$ As the main executor of family intervention, family caregivers played an important role in the long-term management of PLS and have been gradually acknowledged by the society. Studies have shown that with appropriate family care and support, about 50\% PLS can return to a good life state, implying that good family intervention is the basis of rehabilitation. ${ }^{2}$ However, family caregivers also face multiple challenges during their caregiving process, including lack of knowledge of schizophrenia and skills about caregiving, intense relationships and conflicts between PLS and their family members, self-stigma and related social withdrawal and social isolation, lack of professional support in decision-making, etc. ${ }^{3,4}$ Decades of research have confirmed that caring for a PLS often engenders enormous burden, which may lead to an increased risk of depression, anxiety, and even mortality among family caregivers. ${ }^{5-7}$

Family intervention can help relieve the symptoms of PLS and prevent recurrence. Short-term family interventions have been shown to increase family members' knowledge and awareness of schizophrenia, while long-term (9-24 months) family interventions have been shown to reduce the recurrence rate and the number of hospital readmissions of PLS, which can both reduce family burden and improve PLS outcomes. ${ }^{8-10}$ 
The past few decades have seen a growing number of family intervention programs being developed and showing effectiveness in improving family caregiving burden of PLS. ${ }^{11,12}$ Among such programs, three key elements have been identified: (1) Psycho-education to improve the knowledge and skills of schizophrenia and caregiving; (2) Peer-support to exchange experiences and provide mental support; (3) Professional support to provide advice and guidance from clinicians. All three elements have different focuses and targets, and it has been proposed that an integrative intervention model combining all three elements may best serve the purpose of providing all-round support in family caregiving of PLS. ${ }^{13}$ However, how to deliver such an integrative family intervention mode in an accessible, acceptable way remains unknown.

So far, the most traditional way of family intervention delivery is hospital-based intervention, which involves regular health lectures held in hospitals, peer support groups among PLS and caregivers and face-to-face doctor-family consultations. Studies have shown that hospital-based family intervention programs are effective in improving caregiving skills, relieving caregiving stress and burden of caregivers, as well as improving symptoms and functioning, preventing relapse and promoting recovery among PLS. ${ }^{14-17}$ However, the applicability and effectiveness of hospital-based family intervention programs are often limited by geographic and time constraints, as well as other logistics such as transportation and funding.

With the development of the Internet and mobile-mediated communication over the past few decades, mobile phonebased health intervention (mHealth) has gained popularity due to its proven feasibility, effectiveness, and efficacy. ${ }^{18-21}$ In China, health intervention programs based on the most predominant social media-WeChat, a free application that provides multiple powerful instant messaging services including voice and text messaging, voice and video calls, photo sharing, payment and games. ${ }^{4}$ It has over one billion monthly active users of all ages, but the users are not so many in other countries. ${ }^{22}$ Due to its wide range of platforms and functions, WeChat can offer professional guidance, peer or automated support and personalized feedback from therapists or research staff instantly. It has been accessible, affordable, feasible and cost-effective, and has significant effects on the out-of-hospital management of various diseases. ${ }^{4,23}$ Although both hospital-based and WeChat-based family intervention programs have been developed and implemented among various populations, it remains unclear which mode is more acceptable among caregivers of PLS. In fact, just like WeChat, other digital social media, such as Facebook, Whats app or You Tube, can provide many advantages compared with computer-based intervention, including monitoring symptoms before and immediately after the occurrence of critical events, but which one is best depends on the intervention content. ${ }^{24}$

The paper build upon a previous paper published by our team but made more extension.Although both papers belonged to the same large study project, they used different samples, the previous paper used a patient sample of people living with schizophrenia $(n=400)$, while the current study used a caregiver sample of these patients $(n=449)$. Also, the previous paper only examined the WeChat-based mHealth intention and preferences, while the purpose of this study is to assess the preferences for WeChat-based and hospital-based family intervention among caregivers of PLS and identify correlates associated with these preferences. To be specific, we aim to examine and compare the total endorsement rate for each element of WeChat-based and hospital-based family intervention; to explore and compare correlates affecting preferences for WeChat-based and hospital-based family intervention. The findings may provide important implications in designing more targeted, effective, and needs-based family intervention programs to support family caregiving, reduce the burden of family care, improve the physical and mental health well-being of caregivers, and finally, promote the recovery of PLS.

\section{Materials and Methods}

\section{Research Design}

This study was a cross-sectional survey conducted in Ningxiang County of Hunan province between May 2019 to September 2019. The survey via a one-stage cluster-sampling method was offered to family caregivers of people living with schizophrenia who were registered in the local management and treatment of severe mental illnesses program named 686 Program, which was supported by China central government and intended to integrate hospital and community mental health services for serious mental illness, benefiting patients and the public. ${ }^{25}$ 


\section{Setting}

The study was approved by the institutional review board of the Xiangya School of Public Health of Central South University (No.: XYGW-2019-029), and written informed consent was obtained from all participants, which was conducted according to the guidelines of the Declaration of Helsinki.Considering most caregivers had low educational background and it may be difficult to read and understand questionnaires by themselves, face-to-face interviews were conducted by 9 interviewers who were all postgraduates with public health backgrounds from the Xiangya School of Public Health of Central South University. All interviewers received a one-week uniform formal training provided by a psychologist before the formal study.

\section{Population and Sample Size}

Participants were included if they were caring for PLS meeting the diagnostic criteria of Chinese Classification of Mental Disorders -3 (CCMD-3) or International Classification of Diseases -10 (ICD-10) for schizophrenia and are registered in the "686 Program"; are caring for PLS for at least two years; aged over 18 years old; and able to read, write and communicate. A sample of 449 primary family caregivers was recruited from four towns and villages of Ningxiang County through a one-stage cluster sampling method. Details of the study has been published elsewhere. ${ }^{13}$

\section{Sampling Technique}

First, randomly select 3 towns and 1 Xiang (an administrative unit similar to towns but with low socio-economic development) from Ningxiang County, and then conduct cluster sampling of all communities within each town and all villages within each township, and get the total sampling frame of 55 representative communities/villages. This sampling method was used to obtain as representative samples as possible, and to minimize sampling deviation.

\section{Data Collection Instruments Social-Demographic Information}

Social-demographic information was collected using self-designed questionnaires that asked about the caregivers' age (continuous variable), gender (male/female)), kinship with PLS (parents/spouse/children/siblings/ others), marital status (married/not married), employment (yes/no), education (primary and below/middle and high/college and above), family annual income (low/middle/high income classified by quartile), primary caregiver (yes/no), and WeChat use (yes/no).

\section{Preferences for Two Forms of Family Intervention Delivery}

Preferences for two forms of family intervention were evaluated by six yes-no questions. Preference for WeChat-based family intervention was assessed by 3 questions asking participants whether they were willing to acquire psychoeducation through WeChat Official Accounts (WOA), or peer support through WeChat chat groups, or professional support through WeChat private contacts. Participants with any "yes" answer to the above-mentioned three questions were considered as endorsing WeChat-based family interventions. Preference for hospital-based family intervention was assessed by 3 questions asking participants whether they were willing to acquire psychoeducation through lectures, or peer support by support groups, or professional support from home visits by the psychiatrist. Participants with any "yes" answer to the above-mentioned three questions were considered as endorsing hospital-based family interventions. The details can be seen in Appendix 1.

\section{Social Support}

Social support was measured by the Multidimensional Scale of Perceived Social Support (MSPSS) which consists of 12 items, each with a 7-point Likert-type response option that ranges from "very strongly disagree" (1) to "very strongly agree" (7). The MSPSS has three subscales: "Friends" (Questions 6, 7, 9, and 12), "Family" (Questions 3, 4, 8, and 11) and "Significant Others" (Questions 1, 2, 5, and 10). A higher total score indicates a higher level of perceived social support. In the current study, the MSPSS showed good internal consistency with a Cronbach's alpha of 0.88 in the current study and of 0.95 in our study. 


\section{Coping Style}

Coping style was measured using the Simplified Coping Style Questionnaire (SCSQ) [27] which consists of 20 items, each with a 4-point Likert-type response option that ranges from "never" (0) to "frequently" (3). The SCSQ has two subscales, positive coping (items 1-12) and negative coping (items 13-20). A higher total score indicates a higher level of coping. In our study, the SCSQ showed good internal consistency with a Cronbach's alpha of 0.88 .

\section{Data Management and Plan of Analysis}

Descriptive statistics were used to present the characteristics of participants and their preferences towards WeChat-based or hospital-based family intervention, with frequencies and percentages for categorical variables and means \pm standard deviations (SD) for continuous variables. For better comprehension of caregivers' preferences towards WeChat-based and hospital-based family intervention, a univariate analysis was used to explore potential demographic and clinical characteristics associated with each preference. Moreover, logistic regression was applied to identify and compare independent correlates associated with each preference. Odds ratios with $95 \%$ confidence limits (CL) were calculated to compare the strength of the correlations. All analyses were performed using SPSS version 26.0 software for Windows. Statistical significance was defined at a value of $\mathrm{P}<0.05$.

\section{Results}

\section{Characteristics of the Participants}

The questionnaire was completed by 449 participants. The social-demographic and clinical characteristics of all participants are presented in Table 1 . There were slightly more females (54.1\%) than males (45.9\%). Parents and spouses were the main type of kinship, accounting for $80.18 \%$. Most of the caregivers were in the 60-100 age group $(62.36 \%)$, primary caregivers (92.2\%), married (75.72\%), unemployed (85.52\%), and with middle and high school education (61.47\%). Nearly half had middle level of annual household income (49.22\%), and 46.77\% were WeChat users. In addition, participants had a mean score of $50.35 \pm 18.95$ for MSPSS-12, $20.10 \pm 7.70$ for positive coping, and $11.76 \pm 4.59$ for negative coping.

\section{Preferences for WeChat-Based versus Hospital-Based Family Intervention}

Among 449 participants, $44.99 \%$ were interested in both WeChat-based and hospital-based family intervention, $27.17 \%$ preferred hospital-based intervention only, while $5.12 \%$ chose WeChat-based intervention only. In addition, there were still 22.72\% choosing neither WeChat-based nor hospital-based intervention. Overall, $72.16 \%$ of participants endorsed hospital-based family intervention, which was significantly higher than the endorsement rate of WeChat-based family intervention $(72.16 \%$ vs $50.11 \%, P<0.001)$.

Table 2 shows preferences for each of the three elements of WeChat-based versus hospital-based family intervention programs. For both WeChat-based and hospital-based interventions, psychoeducation is the most preferred element with over $70 \%$ of endorsement rate, while over half endorsed peer support and professional support (52.78-57.41\%). Compared to WeChat-based interventions, participants showed slightly higher endorsement rate for hospital-based psychoeducation $(77.47 \%$ vs $75.11 \%$ ) and professional support $(52.78 \%$ vs $56.00 \%)$, while slightly lower endorsement rate for hospital-based peer support (52.78\% vs $56.00 \%)$.

\section{Comparisons of WeChat-Based and Hospital-Based Family Intervention Intentions by Socio-Demographic and Clinical Characteristics}

Table 3 shows differences in acceptability of WeChat-based and hospital-based family intervention by socialdemographic and clinical characteristic. Compared to those who did not support WeChat-based intervention, those who endorsed WeChat-based intervention were younger (52.89\% vs $47.11 \%, P<0.001)$, less likely to be parents $(47.56 \%$ vs $65.63 \%, P<0.001$ ), had higher education (college and above: $12.44 \%$ vs $6.70 \%, P<0.001$ ), more likely to be employed ( $20.00 \%$ vs $8.93 \%, P<0.001$ ), and more likely to use WeChat ( $75.56 \%$ vs $17.86 \%, P<0.001)$. They also had higher social support (56.15 \pm 16.52 vs $44.53 \pm 19.48, P<0.001)$, and more frequently adopted positive coping (21.75 $\pm 7.2218 .43 \pm 7.83$, $P<0.001)$. No significant differences were found for those who endorsed and did not endorse hospital-based intervention, except for higher WeChat use rate in hospital-based intervention endorsing group $(52.47 \%$ vs $32.00 \%, \mathrm{P}<0.001)$. 
Table I Characteristics of All Participants $(n=449)$

\begin{tabular}{|c|c|}
\hline \multirow[t]{2}{*}{ Characteristic } & All Respondents \\
\hline & Mean \pm Sd/N (\%) \\
\hline \multicolumn{2}{|c|}{ Social-demographic characteristics } \\
\hline \multicolumn{2}{|c|}{ Age } \\
\hline $18-59$ & $169(37.64)$ \\
\hline $60-100$ & $280(62.36)$ \\
\hline \multicolumn{2}{|l|}{ Gender } \\
\hline Male & $206(45.90)$ \\
\hline Female & $243(54.10)$ \\
\hline \multicolumn{2}{|l|}{ Kinship } \\
\hline Parents & $254(56.57)$ \\
\hline Spouse & $106(23.61)$ \\
\hline Children & $29(6.46)$ \\
\hline Siblings & $49(10.91)$ \\
\hline Other & II (2.45) \\
\hline \multicolumn{2}{|l|}{ Primary caregivers } \\
\hline No & $35(7.80)$ \\
\hline Yes & $414(92.20)$ \\
\hline \multicolumn{2}{|l|}{ Marriage } \\
\hline Not married & $109(24.28)$ \\
\hline Married & $340(75.72)$ \\
\hline \multicolumn{2}{|l|}{ Education } \\
\hline Primary and below & $130(28.95)$ \\
\hline Middle and high & $276(6 \mid .47)$ \\
\hline College and above & $43(9.58)$ \\
\hline \multicolumn{2}{|l|}{ Employment } \\
\hline Unemployed & $384(85.52)$ \\
\hline Employed & $65(14.48)$ \\
\hline \multicolumn{2}{|l|}{ Family annual income } \\
\hline Low-income & $132(29.40)$ \\
\hline Middle-income & $221(49.22)$ \\
\hline High-income & $96(21.38)$ \\
\hline \multicolumn{2}{|l|}{ WeChat use } \\
\hline No & $239(53.23)$ \\
\hline Yes & $210(46.77)$ \\
\hline \multicolumn{2}{|l|}{ Clinical characteristics } \\
\hline \multicolumn{2}{|l|}{ Social support } \\
\hline MSPSS-12 & $50.35 \pm 18.95$ \\
\hline \multicolumn{2}{|l|}{ Coping } \\
\hline Positive coping & $20.10 \pm 7.70$ \\
\hline Negative coping & $11.76 \pm 4.59$ \\
\hline
\end{tabular}

\section{Correlates of WeChat-Based and Hospital-Based Family Intervention Intentions}

Table 4 shows correlates associated with the acceptability of WeChat-based and hospital-based family intervention by multivariate logistic regressions. Endorsement of WeChat-based family intervention was associated with younger age $(\mathrm{OR}=0.42$, 95\% CI: 0.22, 0.79), WeChat use (OR=12.90, 95\% CI: 7.48, 22.23), and higher social support (OR=1.03, 95\% CI: 1.01, 1.04). Endorsement of hospital-based family intervention was associated with lower education $(\mathrm{OR}=0.19-0.37$, 95\% CI: 0.07, 0.66) and WeChat use (OR=3.27, 95\% CI: 1.91, 5.59). 
Table 2 Preferences for Specific Intervention Programs

\begin{tabular}{|l|c|c|}
\hline Preferences & WeChat-Based $\mathbf{n}(\%)$ & Hospital-Based $\mathbf{n}$ (\%) \\
\hline Any programs & $224(49.89)$ & $125(27.84)$ \\
No & $225(50.11)$ & $324(72.16)$ \\
Yes & $56(24.89)$ & $73(22.53)$ \\
Psychoeducation & $169(75.11)$ & $251(77.47)$ \\
No & $99(44.00)$ & $153(47.23)$ \\
Yes & $126(56.00)$ & $171(52.78)$ \\
Peer support & $98(43.56)$ & $138(42.59)$ \\
No & $127(56.44)$ & $186(57.41)$ \\
Yes & & \\
Professional support & No & \\
Yes & & \\
\hline
\end{tabular}

\section{Discussion}

\section{Summary of the Findings}

To our knowledge, this is the first study to examine and compare the intention and preferences for WeChat-based and hospital-based family interventions among caregivers of PLS and identify correlates of these preferences. Our results showed that over $70 \%$ family caregivers were willing to participate in hospital-based family intervention, while half (50.11\%) endorsed WeChat-based family intervention. For the three elements of family intervention, psychoeducation was the most adopted in both the WeChat-based and hospital-based family intervention. Younger age, WeChat use, and more social support were associated with endorsement of WeChat-based family intervention, while lower education and WeChat use were associated with endorsement of hospital-based family intervention.

\section{Endorsement Rate of WeChat-Based and Hospital-Based Family Intervention}

One major finding is that a higher percentage of caregivers endorsed the traditional hospital-based family intervention than WeChat-based family intervention. More than $70 \%$ of respondents expressed their willingness to try hospital-based family intervention, which was much higher than that of previous studies. ${ }^{26-28}$ The most possible reason may be that caregivers of PLS in our sample were mostly old people with lower education, and are thus less likely to use WeChat and endorse WeChatbased interventions. Another possible explanation may be that the traditional hospital-based intervention has a longer history of implementation, with rich experiences and successful cases being reported and shared by numerous previous studies. As numerous studies have confirmed that hospital-based family intervention can reduce recurrence and improve the outcomes of PLS. $^{29}$ As a result, it is more widely known and accepted by the general public than the newly emerged WeChat-based intervention. However, it should also be pointed out that the face-to-face nature of the survey may lead to the sample being more likely to think that hospital-based family intervention is acceptable. This finding suggests that traditional hospital-based family intervention is the still the most widely accepted way of intervention by the general public, while WeChat-based family intervention also shows great potential to be popularized in the future. ${ }^{30-33}$

Although lower than the endorsement rate of hospital-based intervention, half of participants were willing to accept WeChat-based family intervention, which is higher than the reported $43 \%$ in a previous study on the PLS. Such an endorsement rate was still encouraging, indicating the considerable potential of WeChat-based family intervention for caregivers in addressing the lack of availability of hospital-based mental health services in China. Up to now, in developing countries, there is little experience in providing family interventions to caregivers through social media platforms. Our results provide a first attempt to understand the possible acceptability of WeChat-based family intervention in China and may offer useful insight into future development of mHealth programs. 
Table 3 Social-Demographic and Clinical Characteristics of WeChat-Based and Hospital-Based Family Intervention Intention $(\mathrm{N}=449)^{\mathrm{a}}$

\begin{tabular}{|c|c|c|c|c|c|c|}
\hline \multirow[t]{3}{*}{ Characteristic } & \multicolumn{2}{|c|}{ WeChat-Based Intervention } & \multirow[t]{3}{*}{$\mathbf{p}$} & \multicolumn{2}{|c|}{ Hospital-Based Intervention } & \multirow[t]{3}{*}{$\mathbf{p}$} \\
\hline & No $(n=224)$ & Yes $(n=225)$ & & No $(n=125)$ & Yes $(n=324)$ & \\
\hline & Mean \pm Sd/N (\%) & Mean \pm Sd/N (\%) & & Mean $\pm \mathbf{S d} / \mathbf{N}(\%)$ & Mean $\pm \mathbf{S d} / \mathbf{N}(\%)$ & \\
\hline \multicolumn{7}{|c|}{ Social-demographic characteristics } \\
\hline \multicolumn{7}{|c|}{ Age } \\
\hline $18-59$ & $50(22.32)$ & 119 (52.89) & $<0.001$ & $4 \mathrm{I}(32.80)$ & $128(39.5 \mid)$ & 0.189 \\
\hline $60-100$ & I 74 (77.68) & $106(47.11)$ & & $84(67.02)$ & $196(60.49)$ & \\
\hline \multicolumn{7}{|l|}{ Gender } \\
\hline Male & $104(46.43)$ & $102(45.33)$ & 0.816 & $60(48.00)$ & $146(45.06)$ & 0.575 \\
\hline Female & $120(53.57)$ & $123(54.67)$ & & $65(52.00)$ & $178(54.94)$ & \\
\hline \multicolumn{7}{|l|}{ Kinship } \\
\hline Parents & $147(65.63)$ & $107(47.56)$ & $<0.001$ & 71 (56.80) & $183(56.48)$ & 0.671 \\
\hline Spouse & $44(19.64)$ & $62(27.56)$ & & $32(25.60)$ & $74(22.84)$ & \\
\hline Children & $6(2.68)$ & $23(27.56)$ & & $5(4.00)$ & $24(7.4 I)$ & \\
\hline Siblings & $21(9.38)$ & $28(12.44)$ & & $13(10.40)$ & $36(11.11)$ & \\
\hline Other & $6(2.68)$ & $5(2.22)$ & & $4(3.20)$ & $7(2.16)$ & \\
\hline \multicolumn{7}{|l|}{ Primary caregivers } \\
\hline No & $13(5.80)$ & $22(9.78)$ & 0.116 & $7(5.60)$ & $28(8.64)$ & 0.281 \\
\hline Yes & $211(94.20)$ & $203(90.22)$ & & II 8 (94.40) & $296(91.36)$ & \\
\hline \multicolumn{7}{|l|}{ Marriage } \\
\hline Not married & $60(26.79)$ & $49(21.78)$ & 0.216 & $31(24.80)$ & 78 (24.07) & 0.872 \\
\hline Married & $164(73.21)$ & 176 (78.22) & & $94(75.20)$ & $246(75.93)$ & \\
\hline \multicolumn{7}{|l|}{ Education } \\
\hline Primary and below & 89 (39.73) & $4 I(18.22)$ & $<0.001$ & $28(22.40)$ & $102(31.48)$ & 0.164 \\
\hline Middle and high & $120(53.57)$ & $156(69.33)$ & & $84(67.20)$ & $192(59.26)$ & \\
\hline College and above & $15(6.70)$ & $28(12.44)$ & & $13(10.40)$ & $30(9.26)$ & \\
\hline \multicolumn{7}{|l|}{ Employment } \\
\hline Unemployed & $204(91.07)$ & $180(80.00)$ & 0.001 & $113(90.40)$ & $27 \mid(83.64)$ & 0.068 \\
\hline Employed & $20(8.93)$ & $45(20.00)$ & & $12(9.60)$ & $53(16.36)$ & \\
\hline \multicolumn{7}{|l|}{ Family annual income } \\
\hline Low-income & $67(29.91)$ & $65(28.89)$ & 0.270 & $43(34.40)$ & 89 (27.47) & 0.185 \\
\hline Middle-income & $116(51.79)$ & $105(46.67)$ & & $53(42.40)$ & $168(51.85)$ & \\
\hline High-income & $41(18.30)$ & $55(24.44)$ & & $29(23.20)$ & $67(20.68)$ & \\
\hline \multicolumn{7}{|l|}{ WeChat use } \\
\hline No & $184(82.14)$ & $55(24.44)$ & $<0.001$ & $85(68.00)$ & I54 (47.53) & $<0.001$ \\
\hline Yes & $40(17.86)$ & I $70(75.56)$ & & $40(32.00)$ & $170(52.47)$ & \\
\hline \multicolumn{7}{|l|}{ Clinical characteristics } \\
\hline \multicolumn{7}{|l|}{ Social support } \\
\hline MSPSS-12 & $44.53 \pm 19.48$ & $56.15 \pm 16.52$ & $<0.001$ & $48.17 \pm 20.02$ & $51.14 \pm 18.52$ & 0.169 \\
\hline \multicolumn{7}{|l|}{ Coping } \\
\hline Positive coping & $18.43 \pm 7.83$ & $21.75 \pm 7.22$ & $<0.001$ & II. $.45 \pm 4.6 \mathrm{I}$ & $12.06 \pm 4.57$ & 0.154 \\
\hline Negative coping & $19.16 \pm 8.09$ & $20.45 \pm 7.53$ & 0.254 & $11.75 \pm 5.03$ & II. $.76 \pm 4.43$ & 0.956 \\
\hline
\end{tabular}

Note: ${ }^{a}$ Descriptive statistics were compared with chi-square tests for categorical variables and Wilcoxon rank sum test for continuous variables.

\section{Comparisons of Three Elements of WeChat-Based and Hospital-Based Family Intervention}

For the three elements of WeChat-based and hospital-based family intervention programs, psychoeducation was the most commonly adopted in both the WeChat-based and hospital-based family intervention. This may be explained by the direct effect of psychoeducation in improving knowledge and practical skills so that caregivers can better manage PLS in a more effective way. ${ }^{25}$ However, peer support and professional support were also essential alternative supporting 
Table 4 Multivariate Logistic Regression on Correlates of WeChat-Based and Hospital-Based Family Intervention Intention (N=449) ${ }^{\mathrm{a}}$

\begin{tabular}{|c|c|c|c|c|}
\hline \multirow[t]{2}{*}{ Variable } & \multirow{2}{*}{$\begin{array}{l}\text { WeChat-Based Intention } \\
\text { OR }(95 \% \mathrm{CI})\end{array}$} & \multirow[t]{2}{*}{$\mathbf{p}$} & \multirow{2}{*}{$\begin{array}{l}\text { Hospital-Based Intention } \\
\text { OR }(95 \% \mathrm{Cl})\end{array}$} & \multirow[t]{2}{*}{$\mathbf{p}$} \\
\hline & & & & \\
\hline \multicolumn{5}{|c|}{ Social-demographic characteristics } \\
\hline \multicolumn{5}{|c|}{ Age } \\
\hline $18-59$ & ref & & ref & \\
\hline $60-100$ & $0.42(0.22,0.79)$ & 0.007 & $0.75(0.4 \mathrm{I}, \mathrm{I} .38)$ & 0.355 \\
\hline \multicolumn{5}{|l|}{ Gender } \\
\hline Male & ref & & ref & \\
\hline Female & $\mathrm{I} .06(0.62, \mathrm{I} .8 \mathrm{I})$ & 0.831 & $0.97(0.59,1.57)$ & 0.893 \\
\hline \multicolumn{5}{|l|}{ Kinship } \\
\hline Parents & ref & & ref & \\
\hline Spouse & $1.10(0.55,2.20)$ & 0.797 & $0.50(0.26,0.96)$ & 0.038 \\
\hline Children & I.I6 $(0.35,3.88)$ & 0.805 & $0.76(0.24,2.42)$ & 0.640 \\
\hline Siblings & $0.73(0.30,1.78)$ & 0.491 & $0.78(0.35,1.75)$ & 0.546 \\
\hline Other & $1.57(0.30,8.22)$ & 0.591 & $0.59(0.13,2.77)$ & 0.505 \\
\hline \multicolumn{5}{|l|}{ Primary caregivers } \\
\hline No & ref & & ref & \\
\hline Yes & $0.80(0.31,2.08)$ & 0.645 & $0.82(0.32,2.11)$ & 0.678 \\
\hline \multicolumn{5}{|l|}{ Marriage } \\
\hline Not married & ref & & ref & \\
\hline Married & $1.42(0.75,2.70)$ & 0.281 & $1.15(0.64,2.09)$ & 0.637 \\
\hline \multicolumn{5}{|l|}{ Education } \\
\hline Primary and below & ref & & ref & \\
\hline Middle and high & $1.30(0.73,2.33)$ & 0.375 & $0.37(0.21,0.66)$ & 0.001 \\
\hline College and above & $0.88(0.33,2.39)$ & 0.805 & $0.19(0.07,0.5 \mathrm{I})$ & 0.001 \\
\hline \multicolumn{5}{|l|}{ Employment } \\
\hline Unemployed & ref & & ref & \\
\hline Employed & $0.69(0.30,1.58)$ & 0.383 & $1.27(0.55,2.93)$ & $0.57 I$ \\
\hline \multicolumn{5}{|l|}{ Family annual income } \\
\hline Low-income & ref & & ref & \\
\hline Middle-income & $0.90(0.50,1.63)$ & 0.734 & $1.68(0.98,2.91)$ & 0.061 \\
\hline High-income & $\mathrm{I} .07(0.5 \mathrm{I}, 2.26)$ & 0.858 & $1.02(0.52,1.99)$ & 0.946 \\
\hline \multicolumn{5}{|l|}{ WeChat use } \\
\hline No & ref & & ref & \\
\hline Yes & $12.90(7.48,22.23)$ & $<0.001$ & 3.27 (I.91, 5.59) & $<0.001$ \\
\hline \multicolumn{5}{|l|}{ Clinical characteristics } \\
\hline \multicolumn{5}{|l|}{ Social support } \\
\hline MSPSS-12 & $1.03(1.01,1.04)$ & 0.001 & $1.00(0.99,1.02)$ & 0.483 \\
\hline \multicolumn{5}{|l|}{ Coping } \\
\hline Positive coping & $1.00(0.96,1.04)$ & 0.990 & $1.02(0.98,1.06)$ & 0.347 \\
\hline Negative coping & $1.06(1.00,1.13)$ & 0.063 & $0.99(0.94,1.05)$ & 0.842 \\
\hline
\end{tabular}

Note: ${ }^{a}$ Every clinical characteristic was analyzed with logistic regression after controlling all socio-demographic confounders.

approaches to help family caregiving. ${ }^{34}$ Endorsement of hospital-based interventions were slightly higher than WeChatbased interventions for all elements except for peer support, indicating that peer support may be better realized through WeChat. These findings provide implications for future development of family intervention programs to focus on psychoeducation while also supplementing with peer support and professional support. Another implication is that various forms of family intervention delivery may have different focusing element, for instance, WeChat-based family intervention programs may focus more on peer support, while hospital-based intervention programs may focus more on psychoeducation and professional support. 


\section{Correlates of WeChat-Based and Hospital-Based Family Intervention}

Our studies showed endorsement of WeChat-based family intervention was associated with younger age, WeChat use, and more social support, while endorsement of hospital-based family intervention was associated with lower education and WeChat use. The finding that WeChat users are willing to accept both forms of family interventions reflect the possible equivalent qualities and effects of both forms of interventions among WeChat users. However, people with younger age and more social support were more like to endorse WeChat-based family intervention, ${ }^{35}$ while people with lower education were more likely to endorse hospital-based family intervention. Considering young people were more likely to own and use mobile phones and WeChat, it is not surprising that young people were also more likely to endorse WeChat-based family interventions. The positive effect of social support on endorsement of WeChat-based health interventions implies the fact that social support may be best provided through WeChat since most of social contacts are made through WeChat nowadays. People with lower education may be less competent in navigating WeChat and thus less likely to accept WeChat-based intervention. These findings suggest that various family intervention forms may be developed to target caregivers with various characteristics. For instance, WeChat-based family intervention may be a good option for young family caregivers who can use WeChat and have more social support, while hospital-based family intervention programs may be best suited for older people with lower education.

There are several limitations in this research. First of all, the cross-sectional design of the study makes it difficult to determine causal relationships between preferences and correlates, future longitudinal study is needed to explore predictors of preferences. Secondly, we did not examine other forms of social media such as QQ, ticktock, weibo that were also popular in China. Future studies may include these social medias also to gain a fuller picture of their preferences.

\section{Conclusion}

The studies showed a higher endorsement rate for hospital-based family intervention than WeChat-based family intervention, indicating more room for improvement in popularizing the latter. Different correlates were found for endorsement of hospital-based and WeChat-based family intervention, indicating the need of providing targeted forms of family interventions based on participants' own unique characteristics.

\section{Abbreviations}

CCMD-3, Chinese Classification of Mental Disorders-3; ICD-10, International Classification of Diseases-10; MSPSS, Multidimensional Scale of Perceived Social Support; PLS, people living ith schizophrenia; SCSQ, Simplified Coping Style Questionnaire.

\section{Data Sharing Statement}

The datasets used and/or analysed are available from the corresponding author with a reasonable request.

\section{Ethical Consent}

Institutional Review Committee of Xiangya School of Public Health, Central South University: (XYGW-2019-029) has approved and regulated the ethical implementation of this research.

\section{Disclosure}

The authors report no conflicts of interest in this work.

\section{References}

1. Howes O, Murray R. Schizophrenia: an integrated sociodevelopmental-cognitive model. Lancet. 2014;6736:1-11.

2. Bellack AS. Scientific and consumer models of recovery in schizophrenia: concordance, contrasts, and implications. Schizophr Bull. 2006;32 (3):432-442. doi:10.1093/schbul/sbj044

3. Awad AG, Voruganti LN. The burden of schizophrenia on caregivers: a review. Pharmacoeconomics. 2008;26(2):149-162. doi:10.2165/00019053200826020-00005 
4. Yu Y, Li T, Xi S, et al. Assessing a WeChat-Based Integrative Family Intervention (WIFI) for Schizophrenia: protocol for a Stepped-Wedge Cluster Randomized Trial. JMIR Res Protoc. 2020;9(8):e18538. doi:10.2196/18538

5. Pol MC, Ter Riet G, van Hartingsveldt M, et al. Effectiveness of sensor monitoring in an occupational therapy rehabilitation program for older individuals after hip fracture, the SO-HIP trial: study protocol of a three-arm stepped wedge cluster randomized trial. BMC Health Serv Res. 2017;17(1):3. doi:10.1186/s12913-016-1934-0

6. Piszczek J, Partlow E. Stepped-wedge trial design to evaluate Ebola treatments. Lancet Infect Dis. 2015;15(7):762-776. doi:10.1016/S14733099(15)00078-X

7. Chien WT, Thompson DR, Norman I. Evaluation of a peer-led mutual support group for Chinese families of people with schizophrenia. Am J Community Psychol. 2008;42(1-2):122-134. doi:10.1007/s10464-008-9178-8

8. Bucci S, Berry K, Barrowclough C, et al. Family interventions in psychosis: a review of the evidence and barriers to implementation. Aust Psychol. 2016;51:62-68. doi:10.1111/ap.12172

9. Ma CF, Chien WT, Bressington DT. Family intervention for caregivers of people with recent-onset psychosis: a systematic review and meta-analysis. Early Interv Psychiatry. 2017;12:535-560. doi:10.1111/eip.12494

10. Rathod S, Turkington D. Cognitive- behaviour therapy for schizophrenia: a review. Curr Opin Psychiatry. 2005;18:159-163. doi:10.1097/ 00001504-200503000-00009

11. Petrakis M, Oxley J, Bloom H. Carer psychoeducation in first episode psychosis: evaluation outcomes from a structured group programme. Int J Soc Psychiatry. 2012;59(4):391-397. doi:10.1177/0020764012438476

12. Yesufu-Udechuku A, Harrison B, Mayo-Wilson E, et al. Interventions to improve the experience of caring for people with severe mental illness: systematic review and meta-analysis. Br J Psychiatry. 2015;206(4):268-274. doi:10.1192/bjp.bp.114.147561

13. Zang D-F, Zhang X-T, Yi-lu L, et al. WeChat use among family caregivers of people living with schizophrenia and its relationship to caregiving experiences. J Comput Hum Behav. 2021;123:106877.

14. Nuechterlein KH, Subotnik KL, Ventura J, et al. Enhancing return to work or school after a first episode of schizophrenia: the UCLA RCT of Individual Placement and Support and Workplace Fundamentals Module training. Psychol Med. 2020;50(1):20-28. doi:10.1017/ S0033291718003860

15. Lehman AF, Lieberman JA, Dixon LB, et al.; American Psychiatric Association; Steering Committee on Practice Guidelines. Practice guideline for the treatment of patients with schizophrenia, second edition. Am J Psychiatry. 2004;161(2 Suppl):1-56.

16. Bustillo JR, Lauriello J, Horan WP, et al. The psychosocial treatment of schizophrenia: an update. Am J Psychiatry. 2001;158(2):163-175. doi:10.1176/appi.ajp.158.2.163

17. Pharoah F, Mari J, Rathbone J, et al. Family intervention for schizophrenia. Cochrane Database Syst Rev. 2010;12:CD000088.

18. Firth J, Torous J. Smartphone apps for schizophrenia: a systematic review. JMIR mHealth uHealth. 2015;3(4):e102. doi:10.2196/mhealth.4930

19. Välimäki M, Athanasopoulou C, Lahti M, et al. Effectiveness of social media interventions for people with schizophrenia: a systematic review and meta-analysis. J Med Internet Res. 2016;18(4):e92. doi:10.2196/jmir.5385

20. Naslund JA, Aschbrenner KA, Marsch LA, et al. The future of mental health care: peer-to-peer support and social media. Epidemiol Psychiatr Sci. 2016;25(2):113-122. doi:10.1017/S2045796015001067

21. Lindhiem O, Bennett CB, Rosen D, et al. Mobile technology boosts the effectiveness of psychotherapy and behavioral interventions: a meta-analysis. Behav Modif. 2015;39(6):785-804. doi:10.1177/0145445515595198

22. Wechat: users. Statistic; 2021. http://www.statista.com/statistics/255778/number-of-active-wechat-messenger-accounts/. Accessed February 28, 2022.

23. Ma D, Cheng K, Ding P, et al. Self-management of peripherally inserted central catheters after patient discharge via the WeChat smartphone application: a systematic review and meta-analysis. PLoS One. 2018;13(8):e0202326. doi:10.1371/journal.pone.0202326

24. Stolz T, Schulz A, Krieger T, et al. A mobile app for social anxiety disorder: a three-arm randomized controlled trial comparing mobile and PC-based guided self-help interventions. J Consult Clin Psychol. 2018;86:493-504. doi:10.1037/ccp0000301

25. Suggestions on the Implementation of "Reward Replacing Compensation" Policy to Implement The Guardianship Responsibility of Serious Mental Illness [in Chinese]. Beijing: Chinese Comprehensive Management Office; 2016.

26. Hatfield AB, Gearon JS, Coursey RD. Family members' ratings of the use and value of mental health services: results of a national NAMI survey. Psychiatr Serv. 1996;47:825-831

27. Fulford M, Farhall J. Hospital versus home care for the acutely mentally ill? Preferences of caregivers who have experienced both forms of service. Aust N Z J Psychiatry. 2001;35(5):619-625. doi:10.1080/0004867010060510

28. Al-HadiHasan A, Callaghan P, Lymn JS. Qualitative process evaluation of a psycho-educational intervention targeted at people diagnosed with schizophrenia and their primary caregivers in Jordan. BMC Psychiatry. 2017;17(1):68. doi:10.1186/s12888-017-1225-2

29. Chien WT, Chan SW. The effectiveness of mutual support group intervention for Chinese families of people with schizophrenia: a randomised controlled trial with 24-month follow-up. Int J Nurs Stud. 2013;50(10):1326-1340. doi:10.1016/j.ijnurstu.2013.01.004

30. Kummervold PE, Chronaki CE, Lausen B, et al. eHealth trends in Europe 2005-2007: a population-based survey. J Med Internet Res. 2008;10(4): e42. doi:10.2196/jmir.1023

31. Santana S, Lausen B, Bujnowska-Fedak M, et al. Informed citizen and empowered citizen in health: results from an European survey. BMC Fam Pract. 2011;12:20. doi:10.1186/1471-2296-12-20

32. Barbosa Neves B, Fonseca JRS, Amaro F, et al. Social capital and Internet use in an age comparative perspective with a focus on later life. PLoS One. 2018;13(2):e0192119. doi:10.1371/journal.pone.0192119

33. Krug RR, Xavier AJ, Dorsi E. Factors associated with maintenance of the use of internet, EpiFloripa Idoso longitudinal study. Rev Saude Publica. 2018;52:37. doi:10.11606/S1518-8787.2018052000216

34. Xia J, Merinder LB, Belgamwar MR. Psychoeducation for schizophrenia. Cochrane Database Syst Rev. 2011;6:CD002831.

35. Fortuna KL, Naslund JA, LaCroix JM, et al. Digital peer support mental health interventions for people with a lived experience of a serious mental illness: systematic review. JMIR Ment Health. 2020;7(4):e16460. doi:10.2196/16460 


\section{Publish your work in this journal}

Patient Preference and Adherence is an international, peer-reviewed, open access journal that focusing on the growing importance of patient preference and adherence throughout the therapeutic continuum. Patient satisfaction, acceptability, quality of life, compliance, persistence and their role in developing new therapeutic modalities and compounds to optimize clinical outcomes for existing disease states are major areas of interest for the journal. This journal has been accepted for indexing on PubMed Central. The manuscript management system is completely online and includes a very quick and fair peer-review system, which is all easy to use. Visit http://www.dovepress.com/testimonials.php to read real quotes from published authors.

Submit your manuscript here: https://www.dovepress.com/patient-preference-and-adherence-journal 